\title{
Dissolution and Reprecipitation of Nitrides in an Austenitic Stainless Steel Produced by Powder Metallurgy
}

\author{
Shui L. LEE and Alan HENDRY \\ Metallurgy and Engineering Materials Group, University of Strathclyde, Glasgow, UK.
}

(Received on September 29, 1995; accepted in final form on March 4, 1996)

\begin{abstract}
Production of nitrogen-alloyed AISI 316 steel containing titanium has been studied using a powder metallurgy route. The material is prepared by nitriding titanium-free 316 powder in an ammonia/nitrogen gas mixture at temperatures below $900^{\circ} \mathrm{C}$ and then blending with the titanium alloyed steel to give the required total nitrogen content in the alloy. Alloys with sufficient nitrogen for precipitation of titanium nitride ( TiN) and an excess of $0.2 \% \mathrm{~N}$ in solid solution were prepared. The blend powders were cold isostatically pressed into cylindrical samples and sintered at temperatures between 1100 and $1350^{\circ} \mathrm{C}$. Samples were also extruded at $1200^{\circ} \mathrm{C}$ without prior sintering.

The results show that the titanium alloyed powder is not fully austenitic in the as-sprayed form but the austenite phase is stabilised by the presence of nitrogen. The as-nitrided powder contains a considerable amount of chromium nitride and the microstructure of the sintered or extruded steel is controlled by the behaviour of that phase.

The best conditions for densification are found to be at $1350^{\circ} \mathrm{C}$ in a vacuum furnace with a partial pressure of nitrogen gas applied as the temperature approaches the sintering maximum, followed by a hold for one hour. This gives a material of relatively high density with a controlled nitrogen distribution, high hardness and a fully austenitic structure. During the heating cycle and while the pore structure remains open the vacuum results in the decomposition of some chromium nitride and redistribution of nitrogen into solid solution, but as this is above the atmospheric solubility limit some of it is lost to the atmosphere. The process is limited by the onset of pore closure at maximum sintering temperature. The rate of decomposition of the nitride in the solid state is slow and if the sintering temperature is low then the process of decomposition of the nitrides is incomplete, residual (coarse) chromium nitride remains and the properties are poor. This is also the case in extruded samples which contain remains of the original nitrided particles even after heat treatment. However, when the sintering regime involves liquid phase sintering, the process of dissolution of the original chromium nitride goes to completion, fine titanium nitride remains and a high-density strengthened component is achieved.
\end{abstract}

KEY WORDS: austenite; stainless steel; nitrogen; powder metallurgy.

\section{Introduction}

Processes for production of high-nitrogen steels are in general based on liquid metal routes using overpressure when nitrogen contents above the normal (atmospheric) solubility level are required. However, this then requires close control of the casting stage and subsequent cooling in the solid to avoid loss of nitrogen through the change of solubility with temperatue and the stability of chromium nitride. The present work is part of a programme to obtain austenitic high-nitrogen stainless steels with a distribution of fine titanium nitride for strengthening and avoiding the problems of chromium nitride formation in the manufacturing process. Several methods of achieving this have been investigated and reported in previous Conferences in the present $\operatorname{series}^{1-3)}$ and the use of powder metallurgy is particularly appropriate as is explained below. It is also a suitable method where small quantities of highly-alloyed steels are required and which are to be used in a wrought form.

Wilson ${ }^{4)}$ reported a method of producing powder metallurgy steels of the 25-20Ni-Cr type and a similar approach was demonstrated by Feichtinger ${ }^{5)}$ at HNS 90 as being appropriate to high-nitrogen $\mathrm{Cr}-\mathrm{Mn}$ steels. In the latter paper it was demonstrated that the solid state route can be used not only with powder but also with thin strip when subsequent heat treatment or mechanical deformation is used to overcome the problems of microstructural control. The present authors have explained the basis of the powder process ${ }^{6)}$ and shown that the behaviour on heat treatment can be explained by diffusion of nitrogen in solid solution ${ }^{7)}$ when no strong nitride formers are present. It is clear however from a study of the relative free energies of formation of the nitrides that during the powder nitridation step with ammonia there will be formation of chromium and titanium nitrides in alloys containing those elements and that in many cases iron nitrides will also be formed. 
Table 1. Calculation of gas compositions during reaction.

\begin{tabular}{lllll} 
& Inlet & Outlet & \multicolumn{2}{c}{ Actual Composition } \\
\hline Ammonia & 0.2 & $0.2-x$ & $0.0786(18.2 \%)$ \\
Nitrogen & 0.2 & $0.2+x / 2$ & $0.239(54.9 \%)$ \\
Hydrogen & zero & $3 x / 2$ & $0.117(26.9 \%)$ \\
Total gas & 0.4 & $0.4+x$ & $0.435(100 \%)$
\end{tabular}

Subsequent decomposition of these nitrides and redistribution of the nitrogen in the steel are the critical steps in obtaining a strong, corrosion resistant alloy by this route. The present work therefore examines the behaviour of chromium nitride at different stages of preparation of a Ti-alloyed AISI 316 stainless steel.

The nitriding potential in the present work is dictated by decomposition of ammonia in a flowing ammonia/ nitrogen gas mixture in which the active species for nitriding is ammonia and the nitrogen gas is a carrier. The reaction is,

$$
\mathrm{NH}_{3}=1 / 2 \mathrm{~N}_{2}+3 / 2 \mathrm{H}_{2}
$$

and the partial pressure of nitrogen for nitriding is given by the equilibrium constant (free energy) for the reaction

$$
K(T)=p_{\mathrm{N}_{2}}^{1 / 2} \cdot p_{\mathrm{H}_{2}}^{3 / 2} / p_{\mathrm{NH}_{3}}
$$

To calculate the nitriding potential the gas composition entering and leaving the furnace must be known together with the free energy of formation of ammonia at the nitriding temperature. The following example illustrates the principle of the calculation for the present case at $700^{\circ} \mathrm{C}$.

AISI 316 steel powder $(-106+76 \mu \mathrm{m})$ was nitrided in a gas mixture of inlet composition $50 \% \mathrm{NH}_{3}+50 \% \mathrm{~N}_{2}$ and a total flow rate of $0.4 l \cdot \mathrm{min}^{-1}$. The outlet gas composition varies during the course of the experiment as a function of temperature and state of nitridation of the powder ${ }^{6}$ but at steady state the outlet analyser shows $18.2 \%$ ammonia. Table 1 can then be constructed for the gas compositions in the process.

From the outlet composition column in the Table, the percentage of ammonia in the outlet gas (which is assumed to be that in the hot-zone of the furnace) is given by

$$
\begin{aligned}
\% \mathrm{NH}_{3} & =100 \cdot(1-x) /(2+x) \\
& =\text { Reading of outlet analyser }=18.2 \%
\end{aligned}
$$

Solving this equation gives a value of $x=0.91$ and so the final column of the Table can be calculated to give the actual outlet composition of the gas. From this data it is then possible to calculate the active nitrogen pressure from the equilibrium constant equation given above;

$$
\begin{aligned}
& \Delta G^{\circ}(973 \mathrm{~K})=-58.223 \mathrm{~kJ} \cdot \mathrm{mol}^{-1} \\
& \quad \text { and therefore } K(973 \mathrm{~K})=1346
\end{aligned}
$$

Hence,

$$
p_{\mathrm{N}_{2}}=\left(1346 p_{\mathrm{NH}_{3}} / p_{\mathrm{H}_{2}}^{1.5}\right)=3.56 \cdot 10^{5} \mathrm{~atm}
$$

which is the effective nitriding potential of the gas mixture, although the partial pressure of molecular nitrogen (from Column 3 of the Table) is $0.549 \mathrm{~atm}$. From the Lehrer diagram ${ }^{8)}$ for nitridation of iron it is possible to calculate whether iron nitrides will be formed at this pressure, taking account of the activity of iron in AISI 316 (set equal to its atom fraction), and in this case $\varepsilon-\mathrm{Fe}_{3} \mathrm{~N}$ would be expected. Similar calculations have been carried out for a series of experimental conditions ${ }^{9)}$ and examples of these are used in the discussion below. The stabilities of chromium nitrides are much greater than those of iron nitrides ${ }^{10)}$ and a simple calculation of the limit of ammonia concentration in the gas for formation in AISI 316 can be carried out. This showed that both $\mathrm{Cr}_{2} \mathrm{~N}$ and $\mathrm{CrN}$ are stable at $10^{-3}$ atm of nitrogen at $1100^{\circ} \mathrm{C}$ with the higher nitride increasingly the more stable at higher temperatures and nitrogen pressures. Thus, in the powder nitridation runs in this work, the steel particles will be progressively nitrided from the outer surface by formation of a surface layer of iron nitride and a sub-layer of chromium nitride with excess nitrogen in solid solution. This behaviour has been demonstrated by Billon et al. ${ }^{11)}$ for strip samples of AISI 316.

\section{Experimental}

The powders of AISI 316 were supplied in the form of water or gas atomised particles with a particle size distribution of $(-106+76 \mu \mathrm{m})$ but with some particle fractions available with less than this mean range. These were nitrided in a rotating, tumbling furnace at temperatures of 500,700 or $900^{\circ} \mathrm{C}$ for $1-3 \mathrm{hr}$ in gas mixtures of $25-75 \%$ ammonia in a nitrogen carrier. Before and after nitridation the samples were examined by X-ray diffraction, metallography and nitrogen (inert gas fusion) analysis.

Samples of powder were prepared for densification by blending nitrided, titanium-free 316 with a suitable proportion of $316 \mathrm{Ti}$ to give the required total nitrogen concentration. The Ti-alloyed steel was a conventional AISI 316 containing 2 or $4 \% \mathrm{Ti}$ and the nitrogen content was calculated assuming that all of the titanium was converted to $\mathrm{TiN}$ and that $0.2 \%$ of nitrogen was in excess (solid solution). The blended powder was cold isostatically pressed into $25 \mathrm{~mm}$ diameter billets with minimum binder. Densification was carried out by sintering in a controlled atmosphere, vacuum furnace at temperatures up to $1350^{\circ} \mathrm{C}$ or by extrusion of $25 \mathrm{~mm}$ diameter billets at $1200^{\circ} \mathrm{C}$ and a reduction of $50 \%$.

After densification, some samples were subsequently heat treated to study the stability of the nitrides and of the microstructure. Examination was carried out by conventional microscopy and X-ray methods.

\section{Results and Discussion}

The as-received powder of atomised AISI 316 is fully austenitic but in the compositions containing titanium there is a significant proportion of ferrite resulting from the ferrite stabilisation nature of titanium in iron alloys. Nitriding of the base alloy stock powder produces different phases depending on the conditions. In Fig. 1 the effect of different temperatures and gas compostions 


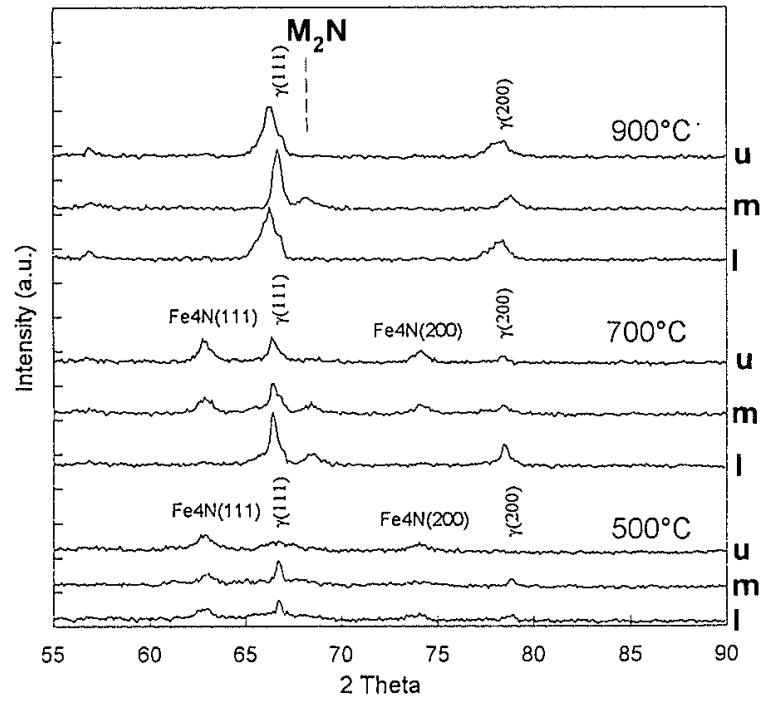

Fig. 1. X-ray diffraction profiles of AISI 316 nitrided at 500 , 700 and $900^{\circ} \mathrm{C}$ for $2 \mathrm{hr}$. For each temperature, curves are shown for the following ammonia concentrations in the gas; $25 \%$ (lower), $50 \%$ (middle) and 75\% (upper).

is shown. It can be seen that at low temperature $\left(500^{\circ} \mathrm{C}\right)$ the particles are covered with a surface layer of $\mathrm{Fe}_{4} \mathrm{~N}$ and that the austenite peaks are lower in intensity due to the thickness of the surface layer. The presence of iron nitride implies the presence of chromium nitride also, as discussed above, although no reflections of these are seen in this case. At $700^{\circ} \mathrm{C}$ and low ammonia content in the gas there is an indication of the presence of an $\varepsilon$ phase $\left(\mathrm{M}_{2} \mathrm{~N}\right)$ shown by the peak to the right of the $(111)_{\gamma}$, but at higher nitrogen contents in the alloy the $\mathrm{Fe}_{4} \mathrm{~N}$ phase, formed on cooling, is more pronounced. This is a kinetic effect rather than control by thermodynamic parameters ${ }^{11}$ and is the result of decomposition of higher nitrides. At $900^{\circ} \mathrm{C}$ the X-ray pattern shows mainly austenite but the peak is broadened by the effect of $(200)_{\mathrm{CrN}}$ which also shows a small peak at $57.5^{\circ}$ of $2 \theta$ $(111)_{\mathrm{CrN}}$. The total nitrogen content of the powder after such treatments varies between a maximum of almost $10 \%$ and approximately $0.2 \%$ when all nitrogen is in solid solution (high-temperature nitriding).

Sintering mixes are then prepared from the nitrided powder and Ti-alloyed 316 to give complete conversion of the titanium to TiN and some excess introgen in solid solution. The principal consideration then lies in the description of the nitrogen (and nitride) distribution in the as-nitrided particles and how that alters during the sintering or extrusion process. The simplest approach to the nitriding of particles is to assume that they are spherical (which is reasonable for gas atomised powders) and that diffusion of nitrogen occurs as a solid solution phenomenon in austenite. Then, from classical solutions of the diffusion laws for the appropriate temperature and using the diffusivity value given by Grieveson and Turkdogan, ${ }^{12)}$ the fractional saturation can be calculated for different sizes of particles at various nitriding times. This data is shown in Fig. 2 for 500,700 and $900^{\circ} \mathrm{C}$ $(773,973$ and $1173 \mathrm{~K})$. It can be seen that for particles in the size range given for these powders at the highest temperature, there is almost complete saturation in about $1 \mathrm{hr}$, while at $700^{\circ} \mathrm{C}(973 \mathrm{~K})$ only particles of less than about $30 \mu \mathrm{m}$ are saturated in that time of treatment. At the lowest temperature, only the surface of the spherical particles is nitrided and the core is effectively nitrogen-free. This simple approach gives an approximate indication of the state of saturation of the particles which act as the nitrogen donors in the subsequent blend and sinter steps. A more rigorous approach is based on the model of Hepworth et al. ${ }^{13)}$ which treats the problem by assuming that the interstitial element diffuses significantly faster than the substitutional, that a stoichiometric nitride is formed and that the rate limiting step is diffusion and not the reaction to form the nitride. For this case, the solution is of the form,

$$
x^{2} \propto\left(\% \mathrm{~N} \cdot D_{\mathrm{N}} \cdot t\right) /(r \cdot \% \mathrm{Cr})
$$

where $\% \mathrm{~N}$ is the surface concentration of nitrogen, $r$ is the stoichiometry ratio in the nitride produced in an alloy of a given $\% \mathrm{Cr}$, the diffusivity of nitrogen is $D_{\mathrm{N}}$ and $x$ is the depth of nitriding after time $t$. This model has been shown ${ }^{14)}$ to apply to austenitic alloys containing titanium and results in a slower rate of penetration of nitrogen than is given by the simple diffusion model. Where iron nitrides are formed on the surface, the effect is to fix the value of the surface concentration of nitrogen at the value in equilibrium with the nitride rather than that given by the nitriding gas. ${ }^{11} \mathrm{~A}$ detailed analysis of the diffusion problems has been carried out by $\mathrm{Lee}^{9)}$ and will be reported elsewhere.

Sintering of the blended powders involves two processes; solid or liquid state densification, and redistribution of the nitrogen between the donor particles and the bulk of the specimen. The results reported below show that there are differences in behaviour which are related to the rate of these processes. Experiments were carried out to determine the optimum regime for solid state sintering and the results led to the following schedule;

(1) $1050^{\circ} \mathrm{C}$ presinter for $1 \mathrm{hr}$ in vacuum,

(2) Introduce a partial pressure of 0.1 atom $\mathrm{N}_{2}$,

(3) $1220^{\circ} \mathrm{C}$ sinter for $30 \mathrm{~min}$.

This gives the following properties for an alloy of AISI $316+2.5 \% \mathrm{Ti}$,

$$
\begin{aligned}
& \text { Green density }=5.12 \mathrm{~g} \cdot \mathrm{cm}^{-3} \\
& \text { Sintered density }=6.77 \mathrm{~g} \cdot \mathrm{cm}^{-3} \\
& \text { Hardness }=195 \mathrm{HV}(10)
\end{aligned}
$$

The alloy after this treatment is approximately $90 \%$ of theoretical density but of greater important there is little evidence of dissolution of chromium nitride inherited from the powder and the formation of TiN is extremely course and heterogeneous. The temperature is well above the thermodynamic dissolution temperature for chromium nitrides ${ }^{10)}$ but the diffusional redistribution of nitrogen is clearly inhibited. The problem has been treated $^{91}$ as the reverse of the nitridation process discussed above where it is now assumed that the nitrided particles are spherical sources of nitrogen releasing the solute into an annular volume surrounding each particle and reacting with titanium according to the Hepworth et al. ${ }^{13)}$ model to produce a dispersion of TiN. In the 
a)

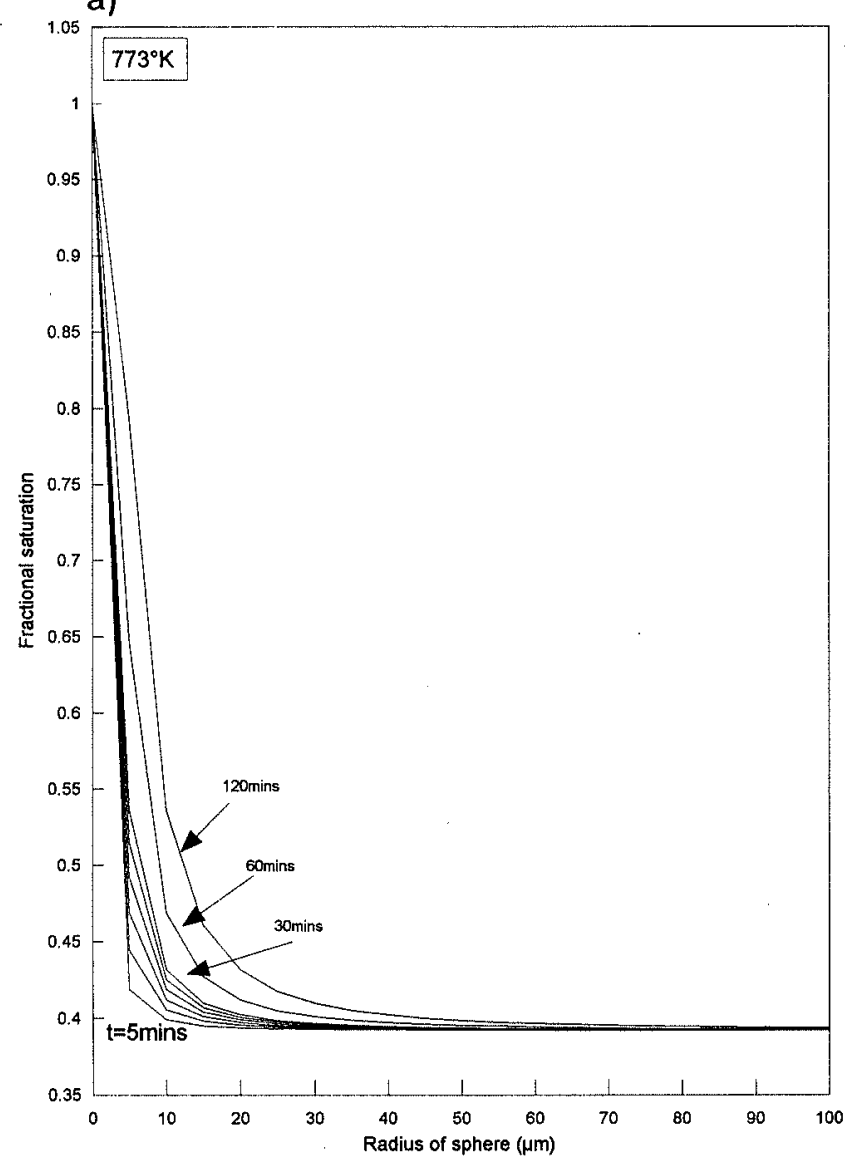

b)



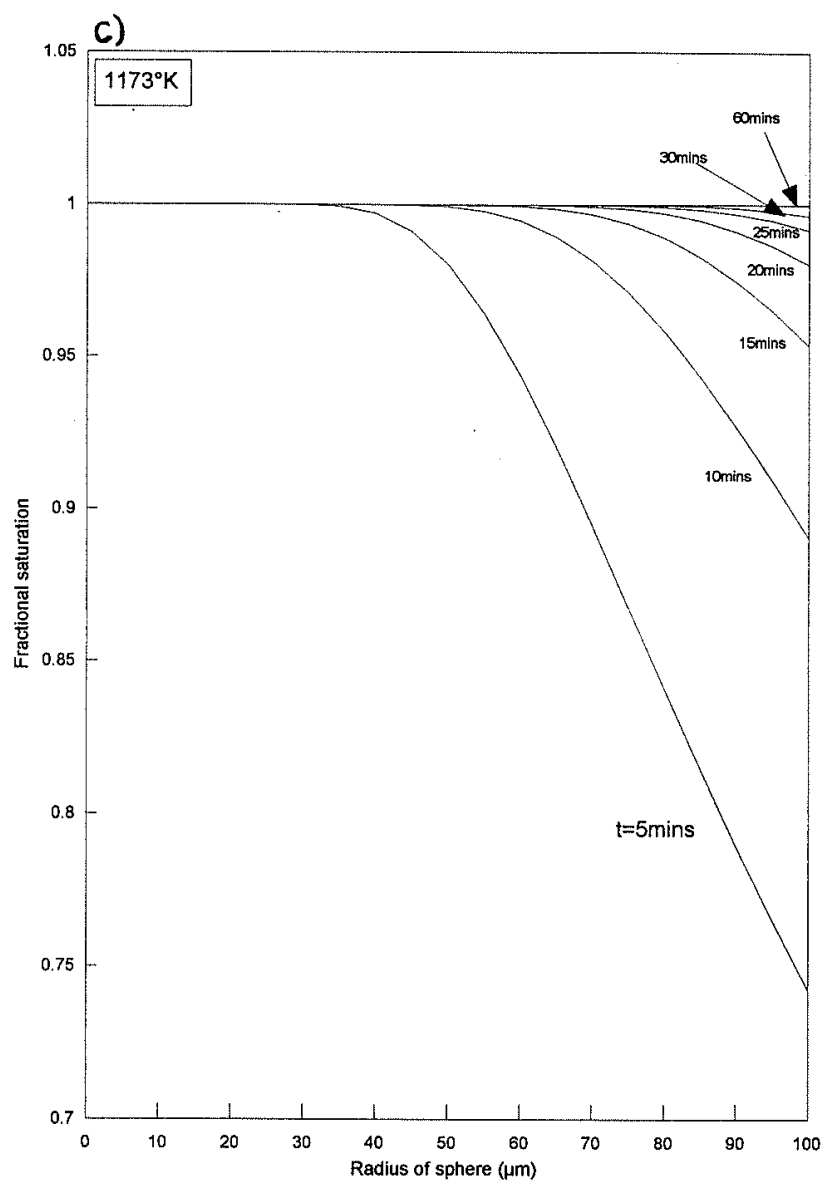

Fig. 2.

Fractional saturation of spherical steel particles calculated for diffusion of nitrogen in austenite at the appropriate temperature.

case of solid state sintering however the matrix is not a continuum as densification is still in progress and even at best $10 \%$ of open porosity remains. Under these conditions the redistribution of nitrogen is not effective and as discussed below in terms of extrusion, there are residual islands of undispersed donor particles. It is clear from this analysis that higher temperature of sintering is necessary to achieve more effective redistribution of nitrogen and so liquid phase sintering was examined. Thermal analysis was used to establish conditions where sufficient liquid was formed in the solidus-liquidus gap for the blended powder to allow densification but without distortion of the sample. The sintering regime was as follows,

(1) $1050^{\circ} \mathrm{C}$ presinter for $1 \mathrm{hr}$ in vacuum,

(2) Introduce a partial pressure of $0.1 \mathrm{~atm} \mathrm{~N}_{2}$,

(3) $1340^{\circ} \mathrm{C}$ sinter for $30 \mathrm{~min}$.

This gives the following properties for the same alloy as above,

(1) Green density $=5.12 \mathrm{~g} \cdot \mathrm{cm}^{-3}$,

(2) Sintered density $=7.29 \mathrm{~g} \cdot \mathrm{cm}^{-3}$,

(3) Hardness $=256 \mathrm{HV}(10)$

In these experiments the samples are almost fully dense and the improved hardness is an indication of this but also of the much improved distribution of strengthening nitrides. An example of such a microstructure is shown in Fig. 3. The mechanism which is believed to apply is 


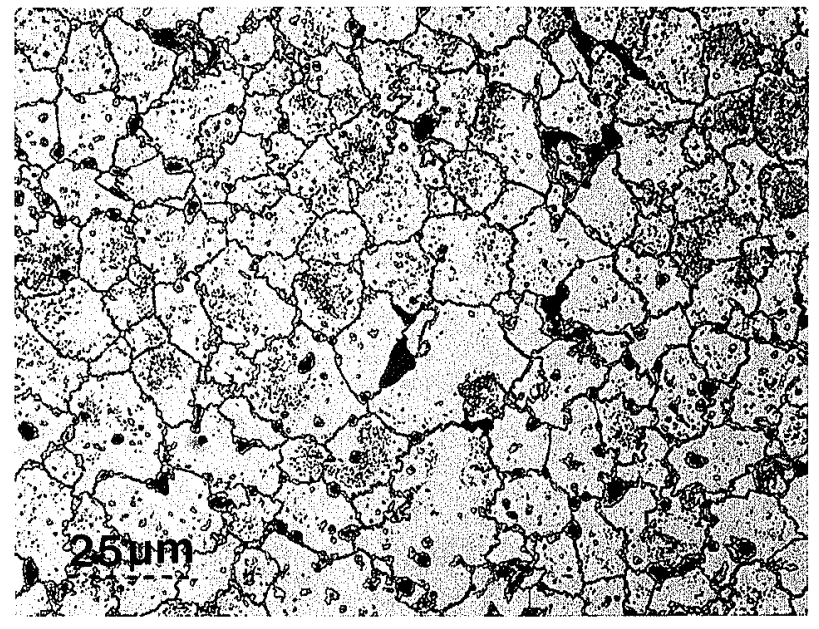

Fig. 3. Optical micrograph of a liquid-phase sintered sample of AISI 316 with the final stage at $1340^{\circ} \mathrm{C}$ for $30 \mathrm{~min}$ as described in the text.

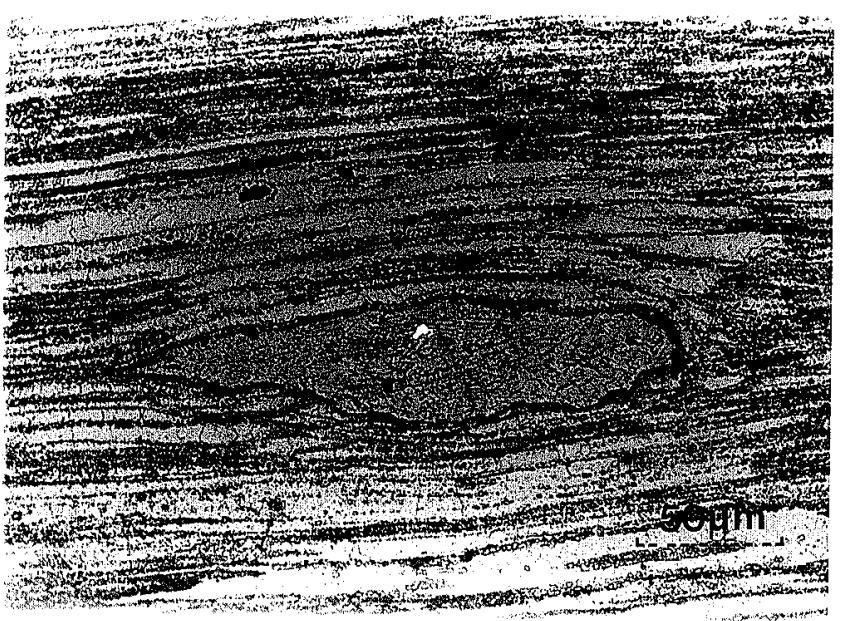

Fig. 4. Optical micrograph of a blended powder which has been extruded at $1200^{\circ} \mathrm{C}$ after $\mathrm{I}$ hr hold at $1200^{\circ} \mathrm{C}$. An undissolved donor particle is visible in the typical extruded microstructure.

as follows. During the heating cycle and while open porosity is present the partial vacuum results in the decomposition of some chromium nitride in both solid and liquid state sintering and the onset of redistribution in the alloy. However in the case of liquid phase sintering, pore closure occurs rapidly, creating a high pore pressure of nitrogen while the liquid volume provides a rapid transport path for both nitrogen and titanium with subsequent precipitation of TiN on cooling. All of which is accompanied by rapid densification and little consequent loss of nitrogen to the atmosphere.

In order to obtain improved mechanical properties by an industrially viable consolidation method, extrusion was also used. The samples were examined by metallography (Fig. 4) and X-ray diffraction as before and tensile test pieces were machined from the consolidated bar. The as-extruded samples $\left(1200^{\circ} \mathrm{C}\right)$ again had a heterogeneous distribution of nitrides, although the effect of extrusion was to give a more uniform general microstructure through working. The results of tensile tests on the extruded bar and after subsequent heat
Table 2. Tensile test data for extruded bar.

\begin{tabular}{lccc}
\hline Sample treatment & $\begin{array}{c}0.2 \% \text { Proof stress } \\
\text { (MPa) }\end{array}$ & $\begin{array}{c}\text { Tensile strength } \\
(\mathrm{MPa})\end{array}$ & $\begin{array}{c}\text { Extension } \\
(\%)\end{array}$ \\
\hline As-extruded & 483 & 605 & 17.5 \\
$1200^{\circ} \mathrm{C}$ for $1 \mathrm{hr}$ & 440 & 575 & 18.8 \\
$1200^{\circ} \mathrm{C}$ for $6 \mathrm{hr}$ & 498 & 654 & 26 \\
$1250^{\circ} \mathrm{C}$ for $6 \mathrm{hr}$ & 487 & 668 & 31 \\
\hline
\end{tabular}

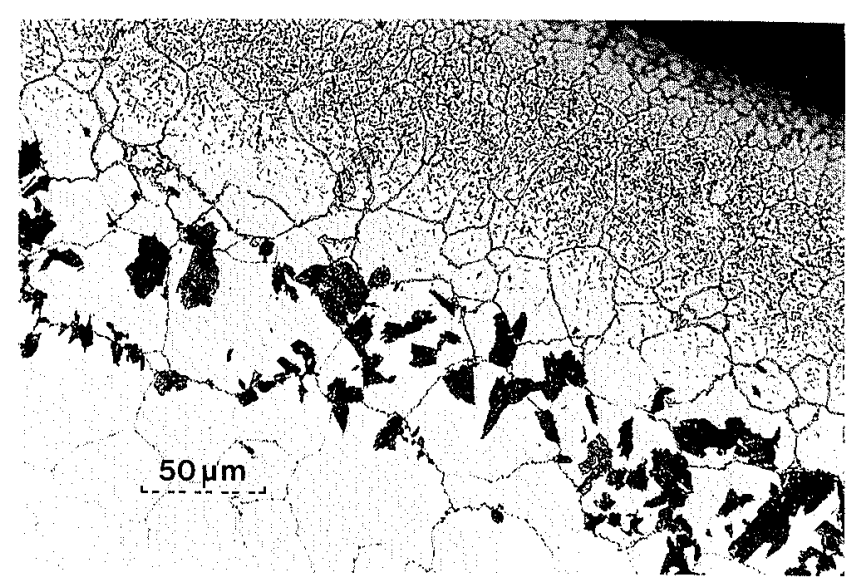

Fig. 5. Optical micrograph of a conventional steel bar nitrided and slow cooled. Retreatment for $15 \mathrm{~min}$ at $1200^{\circ} \mathrm{C}$ (above the nitride solvus) and quenching completely redissolves the nitrides.

treatment are given in Table 2.

There is little change in the properties with heat treatment which indicates that at this temperature and in the solid state the redistribution of the nitrogen is slow. Metallographic examination comfirms that there is residual donor nitride as shown in Fig. 4 which persists through the prolonged treatment at $1250^{\circ} \mathrm{C}$ and which although slowly redissolving under these solid state conditions results in only a small increase in elongation with little change in strength. However, when liquid phase is present these processes can go much more rapidly to conclusion.

In the course of the present investigations, similar nitridation and re-solution treatments have been carried out on rod samples of AISI 316 produced from conventional steelmaking and rolling. Specimens nitrided at high temperature and slow cooled show extensive chromium nitride precipitation in several different morphologies as shown in Fig. 5. Close to the surface there is copious precipitation of chromium nitride in the grain boundaries and in the grains where the nitride appears to be homogeneously nucleated, while at greater depth from the surface there is formation of a cellular precipitate (nitrogen pearlite). There is then an area free of precipitation merging into the core. The same distribution of nitrogen is seen after different nitriding times but the total penetration of the nitrided front increases with time. However, when retreated at $1200^{\circ} \mathrm{C}$ for $15 \mathrm{~min}$ and quenched the nitrides are completely redissolved. There is therefore a completely different set of conditions in the bar samples from those in the sintered or extruded powders and the simple process of dissolution and diffusion (of nitrogen) can proceed 
uninhibited. With the solid-state powder routes, the interfacial conditions between the nitride particles and the un-nitrided matrix particles are quite different, and the transport processes are dominated by these effects. An intermediate state of affairs applies in liquid phase sintering, where the solution and reprecipitation which accompanies that process leads to higher densities, a continuous matrix and (almost) complete redistribution of nitrogen.

\section{Conclusions}

The present results demonstrate that the formation of nitrides and dissolution of nitrogen during nitriding of austenitic steel powder is governed by a model based on the laws of diffusion in which thermodynamic equilibrium in the individual stages is attained. By this means powders can be produced in a controlled manner which can be blended with other alloys to produce a sintering or extrusion stock.

The dissolution and reprecipitation of nitrides during consolidation of the blended powders is however controlled entirely by kinetic factors. At temperatures where the dissolution of iron and chromium nitrides is thermodynamically favourable the microstructure and properties obtained are governed by the transport of solutes through the lattice. In solid state processes such as sintering and extrusion there are residual nitrides present which are not dissolved and these lead to considerable heterogeneities in the structure. By utilising liquidphase sintering, the processes of dissolution and reprecipitation are much closer to completion giving a more uniform material.

It is possible therefore using these methods to produce sintered components which can be used as the stock for further thermo-mechanical processing of high-nitrogen steels and are of particular value where small quantities of specialised compositions are required.

\section{REFERENCES}

1) Proc. of the 1st Int. Conf. on High Nitrogen Steels (HNS '88), ed. by J. Foct and A. Hendry, The Inst. Met., London, (1989).

2) Proc. of the 2nd Int. Conf. on High Nitrogen Steels (HNS '90), ed. by G. Stein and H. Witulski, Stahleisen, Düsseldorf, (1990).

3) Proc. of the 3rd Int. Conf. on High Nitrogen Steels (HNS '93), ed. by V. G. Gavriljik and V. M. Nadutov, Inst. Met. Physics, Ukraine, (1993).

4) E. G. Wilson: Proc. of the 1st Int. Conf. on High Nitrogen Steels (HNS '88), ed. by J. Foct and A. Hendry, The Inst. Met., London, (1989), 305.

5) H. Feichtinger: Proc. of the 2nd Int. Conf. on High Nitrogen Steels (HNS'90), ed. by G. Stein and H. Witulski, Stahleisen, Düsseldorf, (1990), 298.

6) S. L. Lee and A. Hendry: Proc. of the 3rd Int. Conf. on High Nitrogen Steels (HNS '93), ed. by V. G. Gavriljik and V. M. Nadutov, Inst. Met. Physics, Ukraine, (1993), 675.

7) R. F. Irwin and A. Hendry: Mater. Sci. Tech., 10 (1994), 1084.

8) E. Lehrer: Z. Elektrochem., 36 (1930), 383.

9) S. L. Lee: Ph. D. Thesis, University of Strathclyde, (1995)

10) O. Kubaschewski, C. B. Alcock and P. J. Spencer: Materials Thermochemistry, Pergammon Press, Oxford, (1993).

11) B. Billon and A. Hendry: Surface Eng., 1 (1985), 114.

12) P. Grieveson and E. T. Turkdogan: Trans. AIME, 230 (1964), 407.

13) M. T. Hepworth, R. P. Smith and E. T. Turkdogan: Trans. AIME, 236, (1966), 1278.

14) D. C. Unthank, J. H. Driver and K. H. Jack: Met. Sci., 8 (1974), 209. 